\title{
Contributions to the Portuguese National Plan for Patient Safety 2021-2026: A Robust Methodology Based on the Mixed-Method Approach
}

\author{
Paulo Sousa ${ }^{a, b}$ Sofia Guerra Paiva ${ }^{a, b}$ Maria João Lobão a, b, c \\ Ana Luísa Van-Innis ${ }^{d}$ Carla Pereira ${ }^{a}, b, e$ Válter Fonseca ${ }^{e, f}$ \\ apublic Health Research Centre, National School of Public Health, NOVA University of Lisbon, Lisbon, Portugal; \\ ${ }^{b}$ Comprehensive Health Research Center, NOVA Medical School, Lisbon, Portugal; ' Internal Medicine Department,

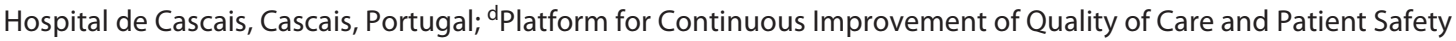 \\ (PAQS ASBL), Brussels, Belgium; 'Department for Quality in Health, Directorate-General of Health, Lisbon, Portugal; \\ ${ }^{f}$ Faculty of Medicine, University of Lisbon, Lisbon, Portugal
}

\section{Keywords}

Patient safety · Strategic plan · Adverse events · Quality of health

\begin{abstract}
Introduction: Several countries prioritize patient safety in their health policies. In Portugal, following the implementation of the National Plan for Patient Safety (NPPS) 20152020, the research team of the National School of Public Health (NSPH) carried out extensive work to continue improving aspects of the previous Plan. This work was focused on identifying the strengths and weaknesses of NPPS 20152020 and aspects related to its applicability and main challenges and opportunities for the implementation of the NPPS 2021-2026. Methods: Methodological dynamic process was based on the most relevant international and national guidelines and the feedback from key patient safety stakeholders. We developed a cross-sectional mixed-methods study from January to August 2021. We used documentation and periodical reports from National Health Service (NHS) healthcare institutions as secondary sources of information. For primary data collection, we used an online survey (applied to elements in the different quality and safety structures of hospitals and primary care units), interviews,
\end{abstract}

and focus groups to collect information from patient safety experts. Results and Discussion: Strengthening safety culture, patient safety training, communication, leadership involvement, patient and family engagement, and monitorization process is considered essential. We also identified local limitations such as the lack of resources and protected time for the healthcare professionals and lack of leadership involvement on patient safety strategies for dedicating to patient safety actions. Most of the patient safety stakeholders agreed that the safety and health of clinical teams and new modalities of healthcare (such as telemedicine, home hospitalization, home care) should be a priority for patient safety strategies. Conclusions: In our study, we used a robust methodology with a participatory process involving different stakeholders. An alignment between local, regional, and national levels in terms of measuring indicators, the definition of priorities, and actions and activities to improve patient safety is recommended. Reinforced partnerships and alignment between the institution's mission, and safety priorities will be crucial to enhance patient safety. Additionally, this work highlights the added value for health systems achieved through strong partnerships between public administration and academic institutions to improve healthcare quality and patient safety.

(c) 2022 The Author(s). Published by S. Karger AG, Basel on behalf of NOVA National School of Public Health
Karger@karger.com www.karger.com/pjp

Karger $\frac{1}{\%}$

BOPEN ACCESS (c) 2022 The Author(s). Published by S. Karger AG, Basel on behalf of NOVA National School of Public Health

This is an Open Access article licensed under the Creative Commons Attribution-NonCommercial-4.0 International License (CC BY-NC) (http://www.karger.com/Services/OpenAccessLicense), applicable to the online version of the article only. Usage and distribution for commercial purposes requires written permission.
Correspondence to:

Paulo Sousa, paulo.sousa@ensp.unl.pt 
Contributos para o Plano Estratégico da Segurança dos Doentes 2021-2026: Uma metodologia robusta baseada numa abordagem de métodos mistos

\section{Palavras Chave}

Segurança do doente · Planos estratégico · Eventos adversos · Qualidade em saúde

\section{Resumo}

Introdução: Vários países têm priorizado a Segurança do Doente no contexto das políticas de saúde. A definição de um plano estratégico, enquanto ferramenta válida e útil para orientar a ação das organizações de saúde, é um processo muito importante para definir prioridades, identificar as ações a ser implementadas e o papel que cada parceiro deve assumir. Em Portugal, concretizado o Plano Nacional para a Segurança dos Doentes (PNSD) 2015-2020, tornou-se necessário desenvolver uma proposta, que assentasse numa metodologia robusta e participativa, para a definição do novo Plano estratégico para a segurança dos doentes. Métodos: A metodologia aplicada privilegiou a revisão de literatura científica e de orientações internacionais e nacionais e o feedback dos principais stakeholders na área. Optouse por um estudo transversal de metodologia mista. Como fontes secundárias de informação, utilizamos documentação oficial, relatórios institucionais e revisão de literatura científica. Os dados primários, foram recolhidos por intermédio de questionário (aplicado aos elementos das Comissões de Qualidade e Segurança de hospitais e ACES do SNS); realizaram-se entrevistas e focus group a especialistas na área segurança do doente. Resultados e discussão: É fundamental reforçar a cultura de segurança e a formação na área da segurança do doente; melhorar a comunicação; aumentar o envolvimento da liderança e promover a participação do doente/ família. A nível local, identificamos falta de recursos, de tempo protegido e falta de envolvimento da liderança nas estratégias de segurança do doente. Conclusões: Neste estudo aplicou-se uma metodologia robusta num processo participativo que envolveu diferentes parceiros com interesse e responsabilidade na área da segurança dos doentes. Recomenda-se um alinhamento entre os níveis local/ regional/nacional, para concretizar a monitorização dos indicadores e definir prioridades, ações e atividades na área da segurança do doente. O reforço de parcerias e o alinhamento entre a missão das organizações de saúde e as prioridades definidas no PNSD 2021-2026 serão cruciais para melhorar a segurança do doente.

C 2022 The Author(s). Published by S. Karger AG, Basel on behalf of NOVA National School of Public Health

\section{Introduction}

Two decades ago, the report from the Institute of Medicine (IOM) "To Err is Human: Building a Safer Health System" highlighted the incidence of medical errors and preventable deaths in healthcare [1]. Since then, patient safety, defined as the absence of preventable harm to patients during the process of healthcare, has been increasingly recognized as a key priority in the global health agenda [2]. As a result, several countries around the world have developed and implemented national strategic plans to address health and patient safety issues, for example, Switzerland [3], Belgium [4], England [5], Scotland [6], Spain [7], Ireland [8], Australia [9], Finland [10], and Portugal.

At the international level, a considerable response was spurred, namely through the establishment of the World Health Organization's (WHO) World Alliance for Patient Safety in 2004 and the initiatives of several other countries. The main purpose of the Alliance was to coordinate, spread, and accelerate improvements within the patient safety area in all WHO member states [11]. At the same time, other international organizations such as the Organization for Economic Co-operation and Development (OECD), the Institute for Healthcare Improvement (IHI), and the International Society for Quality in Health Care (ISQua) have also been developing other initiatives that have greatly contributed to place patient safety on top of the health policies' agendas.

In the last years, several steps have been taken - the WHO's three challenges are good examples to reinforce the importance of clinical safety: clean care is safer care (to reduce healthcare-acquired infections), safe surgery saves lives (to strengthen safety surgery), and medication without harm (to improve medication safety in all steps, from prescription to administration). Efforts have been focused on estimating costs and the economic impact of adverse events [12-15]. The evidence resulting from studies by the OECD have been crucial to helping the decision-making process as it also considers economic factors [13-15].

In the last two years, important and consistent steps have been taken towards the development of a strategic plan for patient safety during the next decade.

In 2019, the 72nd World Health Assembly (WHA) adopted the resolution WHA72.6 on global action on patient safety recognizing that improving and ensuring patient safety is a growing challenge to health service delivery globally. 
In May 2021, The Global Patient Safety Action Plan 2021-2030 was approved at the 74th WHA to provide the Member States and other stakeholders with an action-oriented framework to facilitate the implementation of strategic patient safety interventions at all levels of the health systems over the next 10 years (2021-2030) [16].

This ten-year plan, which is built on five guiding principles and seven strategic objectives, outlines the scale of the patient safety challenge the world is facing globally and sets out a goal for the next 10 years for achieving the maximum possible reduction in avoidable harm as a result of unsafe care. This action plan also provides a framework for countries to develop their respective national action plans on patient safety, as well as to align existing strategic instruments for improving patient safety in all clinical and health-related programs [16].

The European Union Council published its first Recommendation on patient safety in 2009 [17], urging the Member States to take action along four cornerstone areas: i) national patient safety strategic plans, ii) adverse events reporting systems, iii) patient empowerment, and iv) training for the health workforce. Following this recommendation, several European countries included patient safety as a priority on their national health agendas.

While progress has been made in addressing safety challenges since the publication of the IOM report, adverse events remain an everyday reality in healthcare settings all over the world [18-20]. In addition, new safety challenges have emerged in the last decades, such as outpatient care, antimicrobial resistance, budget constraints, increasingly complex care, diagnostic errors, and the use of digital technologies [21].

It is well established that healthcare services around the world occasionally and unintentionally harm patients. In the last two decades, different studies have estimated that around $4 \%$ to $17 \%$ of hospital admissions have resulted in adverse events and that up to half of these were preventable events. [22, 23]

As a result, addressing patient safety represents an important challenge that is gathering attention from the public health perspective. No matter what systems and precautions are put into place, it must be recognized that healthcare providers will always involve risks and the consequence of accepting those risks will have strong clinical, social, and economic impacts [24].

In Portugal, the magnitude, typologies, and nature of adverse events (AE) have been characterized in studies developed during the last decade. Some of those studies focused on a specific type of $\mathrm{AE}$ (related to medication) $[25,26]$ and others analyzed all types of $\operatorname{AE}[23,27]$.

Contributions to the Portuguese NPPS 2021-2026
A study developed in several acute public hospital centers in Portugal identified a $12.5 \%$ [23] total rate of AE. The majority of $\mathrm{AE}$ (66.1\%) occurred in patients aged 65 or older [23]. Of all AE, 39.7\% were related to hospitalacquired infections, followed by $26.7 \%$ associated with surgical procedures and $9.8 \%$ related to medication [23]. The majority of AE (67.4\%) did not result in any significant physical impairment or disability and were resolved during the hospital admission period [23]. However, a small but significant proportion of patients died or experienced a permanent disability as a result of their $\mathrm{AE}$ (12.5\% and 3.0\%, respectively) [23]. The majority of patients (60.8\%) who experienced AEs prolonged their hospitalization on average by 9.6 days, with an estimated addition of EUR 1.9 million [23]. Hospital adverse events continue to be an important public health issue, constituting a burden in terms of clinical, economic, and social impact and, for that reason, they are a challenge for the health system not only in Portugal but also worldwide [23].

Quality of care and patient safety is also a priority for the Portuguese health system (PHS) and this is reflected by the policies and strategies addressing quality defined by the Department for Quality in Health (DQH), at the Directorate-General of Health (DGH). The DQH is responsible for ensuring, coordinating, and evaluating activities and programs of continuous improvement and patient safety. The two key national documents on quality and safety are the National Strategy for Health Quality (NSHQ) and the National Plan for Patient Safety (NPPS). The first NSHQ was published in 2009 by the Ministry of Health and aims to reinforce the equity cost as the core dimension of the national healthcare system in a continuous improvement of quality and safety [28]. The NPPS 2015-2020, aligned with the NSHQ, aimed at supporting managers and clinical practitioners in the PHS to adopt strategies and apply methods for managing the risks associated with healthcare provision. The NPPS 2015-2020 included nine strategic objectives, goals, and actions to be developed by all healthcare organizations of the NHS [28]. Under this framework, a national reporting system (the NOTIFIC@ platform) for safety incidents was also implemented, on a voluntary and thus confidential basis, to safeguard the person reporting, with the publication of the DGH norm 15/2014, 25th September. The Plan was based on a comprehensive vision of the PHS and required serious commitment from all levels of the healthcare governance, coordination, and practice, to harmonize the existing approaches with the management of healthcare provision-associated risks. 
Table 1. Methods description and application

\begin{tabular}{|c|c|c|}
\hline Method & Sources of information & Application \\
\hline Literature review & $\begin{array}{l}\text { National and international guidelines and strategic } \\
\text { documentation; scientific articles available in relevant } \\
\text { databases }\end{array}$ & $\begin{array}{l}\text { The literature review was carried out in a systematic and thorough } \\
\text { manner, allowing the integration of the information from the } \\
\text { different sources throughout the process. }\end{array}$ \\
\hline $\begin{array}{l}\text { Periodical reports } \\
\text { review }\end{array}$ & $\begin{array}{l}\text { Annual reports of the NPPS } 2015-2020 \text { (at the DQH/DGH) } \\
\text { were analyzed by the Nursing School of Lisbon (ESEL) team, } \\
\text { namely with regard to the fulfillment of the agreed targets } \\
\text { from the previous national strategic plan. }\end{array}$ & $\begin{array}{l}\text { This documentation was carefully analyzed by the ESEL research } \\
\text { team and allowed to identify the strengths and weaknesses of the } \\
\text { NPPS 2015-2020, namely the difficulties and limitations in } \\
\text { systematically measuring the existing indicators. Moreover, it also } \\
\text { contributed to characterize the existing patient safety context in } \\
\text { Portugal. }\end{array}$ \\
\hline Online survey & $\begin{array}{l}\text { The online survey was applied to the: } \\
\text { a) Elements of the Quality and Safety Committees of } \\
\text { Hospitals, Local Health Units (LHU), and primary care settings; } \\
\text { b) Elements of the Pharmacy and Therapeutics Committees; } \\
\text { c) Elements of the Local Coordination Groups of the } \\
\text { Prevention and Control of Infection and Antimicrobial } \\
\text { Resistance Program (GCL-PPCIRA); } \\
\text { d) Elements of the Quality Offices/Departments in Patient } \\
\text { Health and Safety/Risk Management; } \\
\text { e) Local Managers for the Notific@ platform }\end{array}$ & $\begin{array}{l}\text { A survey with } 90 \text { questions was developed and validated. This was } \\
\text { applied using the Survey Monkey Platform. The questions were } \\
\text { divided into four main domains: i) general characterization of the } \\
\text { population; ii) aspects related to the 2015-2020 NPPS } \\
\text { implementation and the articulation between the local, regional, } \\
\text { and national levels of care; iii) strategic objectives, recommended } \\
\text { actions, and defined goals developed according with the 2015- } \\
2020 \text { NPPS; iv) suggestions and priorities for the NPPS 2021-2026. } \\
\text { Participants were contacted by institutional DQH/DGH e-mail. The } \\
\text { participants were ensured to maintain anonymous contacts and } \\
\text { provided the consent to participate. The data was collected and } \\
\text { analyzed by the NSPH research team. }\end{array}$ \\
\hline Interviews & $\begin{array}{l}\text { Semi structured online interviews to: i) the heads of } \\
\text { institutions under the direct and indirect administration of } \\
\text { the Ministry of Health and with relevance and interest in the } \\
\text { patient safety field; ii) the heads/experts from regional } \\
\text { healthcare institutions; iii) national experts and academia; iv) } \\
\text { those responsible for elaborating strategic plans at the } \\
\text { international level; v) professional associations }\end{array}$ & $\begin{array}{l}\text { The zoom platform was used for conduction the interviews. These } \\
\text { were conducted by } 2 \text { independent researchers and the audio/video } \\
\text { was not recorded. The content analysis was based on a duly filled } \\
\text { Excel document. } \\
\text { The questions were focused on the following topics: i) positive } \\
\text { aspects of the NPPS 2015-2020; ii) difficulties in following the NPPS } \\
2015-2020 \text { guidelines, strategic objectives, recommended actions, } \\
\text { and achieved goals and indicators; iii) recommendation for the } \\
\text { NPPS 2021-2026. }\end{array}$ \\
\hline
\end{tabular}

In the last quarter of 2020, the DQH/DGH requested the National School of Public Health (NSPH-NOVA) to present a proposal for the next NPPS, to give continuity and improve the patient safety strategic planning, which had started in 2015 with the development and implementation of the NPPS 2015-2020.

The main objective was to describe the strengths and weaknesses of the NPPS (2015-2020), its strategic goals, and the relevant aspects (barriers and facilitators) for its implementation in the healthcare institutions. It was also sought to understand the main challenges and opportunities for the improvement of the NPPS 2021-2026.

\section{Methodology}

We developed a cross-sectional mixed-method study. This study used different data sources for developing a proposal for a conceptual and operational framework for the elaboration of NPPS 2021-2026. This was a methodologic dynamic process based on the most relevant and recent international and national guide- 
Fig. 1. Methodological process.

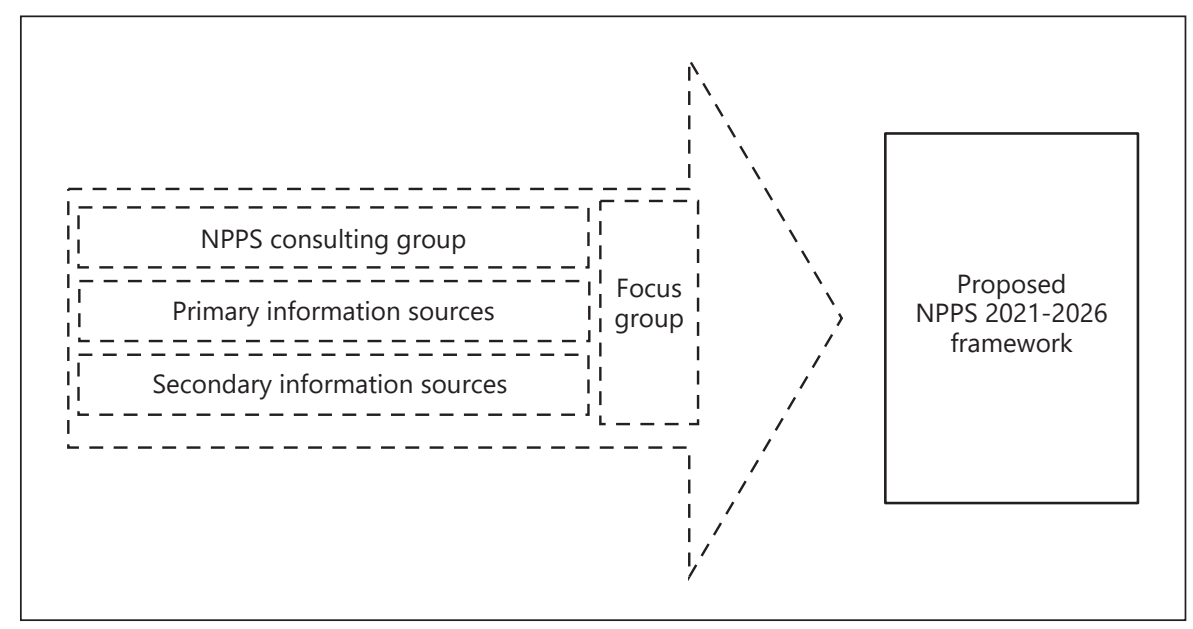

lines and the feedback from the key patient safety stakeholders, in the many different healthcare settings, as well as from the lessons learned with the NPPS 2015-2020.

Concerning the literature review we used as a secondary information source, the periodical institutional reports documents and searched on scientific databases and relevant websites for the best international literature. We also used quantitative and qualitative (use of qualitative data to explore quantitative findings) primary sources of information to complement the literature and documentation consulted.

For quantitative data collection, we developed and applied an online survey to the Quality and Safety Committees (Comissões de Qualidade e Segurança), at the hospitals and primary healthcare institutions. This online survey focused on collecting information regarding the previous NPPS 2015-2020 and identifying future challenges and opportunities for improvement in the next NPPS 2021-2026 (Table 1). In addition, semi-structured interviews were conducted with institutional leaders and patient safety experts on national and international levels from different fields of action to understand their perceptions about the previous strategic plan and opportunities for the next NPPS and also to explore findings obtained with the survey.

After collecting the relevant information, we used focus group sessions for discussing the practical aspects of the framework proposal with experts from different healthcare levels.

An external consulting group was created by the DQH/DGH, whose coordinator was a member of the NSPH-NOVA team, to contribute to the NPPS 2021-2026 framework proposal. The group included elements from different backgrounds such as Medicine, Nursing, Health Technologies, Pharmaceutical Sciences, Hospital Administration, and Law, with vast experience in Quality of Care and Patient Safety - in academic, research, and frontline levels such as primary care units, hospitals, and continuous and integrated care institutions.

In Figure 1 we illustrate the described methodological process.

Table 1 describes each of the methods used in the methodological process.

\section{Results}

\section{Literature Review Results}

International patient safety strategic documents and orientations were consulted to better understand the main current practices and opportunities for improvement in the next NPPS (2021-2026). Based on this research we found that strengthening safety culture, patient safety training, communication, leadership, and adverse event notification were the most highlighted areas in international and national scope $[5-8,10,16,29]$.

Patient safety actions development and implementation should follow a continuous cycle of planning, implementation, monitorization, and analysis [10]

There is also the need for adapting patient safety strategies and actions to specific intervention areas (mental health, neonatology, pediatrics, and others ) [5].

\section{NPPS 2015-2020 Periodical Reports Review}

We analyzed reports from 4 years of NPPS implementation (from 2015 to 2020) in hospital centers, local hospitals, primary healthcare, and local health units. Raw data were analyzed by the Nursing School of Lisbon (ESEL) team, a partner of DQH/DGH for the NPPS 2015-2020 evaluation.

The main results from the patient safety annual reports of healthcare institutions are focused on the positive aspects, barriers, and improvement recommendations for the next NPPS.

Globally there was an increase in patient safety awareness initiatives and concrete patient safety actions implementation in healthcare organizations. Also, the increased number of monitoring reports on an institution- 
Table 2. Sample distribution

\begin{tabular}{ll}
\hline Portugal administrative region & Number of participants (\%) \\
\hline North & $129(38.17 \%)$ \\
Lisbon & $107(31.66 \%)$ \\
Centre & $62(18.34 \%)$ \\
Algarve & $23(6.8 \%)$ \\
Alentejo & $17(5.03 \%)$ \\
Total & $338(100 \%)$ \\
\hline
\end{tabular}

al level allowed to assess periodically the implementation process and outcomes.

On the other hand, the anonymity of results and limited access to some indicators sources for assessing the achievement of patient safety goals were considered barriers for monitorization process in healthcare institutions/departments/units, which can decrease the applicability of the NPPS in the long term. This is considered a limitation for understanding the actual reality in health institutions and is mentioned as a barrier to the continuous improvement of patient safety actions. Also, there is a communication lack of audit results, which can be a limitation for future improvement measures.

In this sense, an alignment between institutional indicators and national level strategies is recommended. There is also the need to increase patient safety practices adherence in primary healthcare settings and other nonhospitalized levels of care, as well as good communications practices.

\section{Data Collection - Online Survey}

i) General Characterization of Population

The online survey was sent to 95 Presidents of the Quality and Safety Committees (from 49 hospitals and 46 primary healthcare) and the collaboration of all health professionals who are part of the quality safety and risk management teams was requested.

We received a total of 338 completed and validated surveys. The geographic distribution of the respondents is detailed in Table 2.

The survey was administered to frontline professionals working on quality and safety committees in hospitals and primary care units. Table 3 presents the descriptive characteristics of participants. We used close-ended and open-ended questions to understand participants' views and perceptions about the previous NPPS (2015-2020) through different domains of implementation and its organization context suitability. ii) Aspects Related to the Implementation of 20152020 NPPS and the Articulation between the Local, Regional, and National Levels

a) Clinical Teams and Leaders/Managers Involvement in Patient Safety Actions. Our results showed weaknesses in the involvement and participation of the leaders/management in strategic planning and execution of the patient safety actions.

The culture of monitoring and improving patient safety is still not a priority in healthcare institutions. This is considered as the main contributing cause of the lack of leadership gap involvement by $37.3 \%(n=126)$ of the participants who considered that there is moderate/weak/ very weak leadership involvement. In addition, the lack of alignment with the institution's mission and/or strategic plan $(n=63 ; 18.6 \%)$ and lack of prioritization by the leaders $(n=78 ; 23.1 \%)$ are also mentioned as two of the main limitations.

Similarly, clinical teams' involvement in patient safety action is considered moderate/weak/very weak by $80.5 \%$ $(n=272)$ of respondents.

The main contributing causes to the low level of team participation were: lack of human resources and/or time dedicated/reserved for these tasks/actions $(n=226$; $66.9 \%)$, communication failures between the various institutional structures, departments, services, and units ( $n$ $=146 ; 43.2 \%)$, problems related to technical resources, information systems $(n=111 ; 32.8 \%)$, and the lack of institutional prioritization $(n=78 ; 23.1 \%)$.

b) Institutional Dissemination. Regarding the institutional NPPS (2015-2020) dissemination, $80.5 \%(n=272)$ of respondents considered the dissemination aspect moderate/weak/very weak. To improve the institutional dissemination, most respondents underline the importance of reinforcing communication between the quality safety committee and other related units and the various institutional units/departments $(n=221 ; 65.4 \%)$. Respondents also referred to the importance of increasing awareness and commitment of institutional leaders $(n=194$; $57.4 \% ; n=176,52.1 \%$.) In addition, respondents also considered the NPPS 2015-2020 dissemination through institutional digital platforms (e.g., intranet) as an important way to improve awareness and involvement of health professionals throughout the organization $(n=167$; 49.4\%).

c) Resources and Organizational Conditions. Most of the respondents $(81.1 \% ; n=274)$ considered the availability of resources and conditions necessary for the development of NPPS 2015-2020 recommended actions as moderate/weak/very weak. Only $11.5 \%$ ( $n=$ 


\begin{tabular}{ll}
\hline Sample characteristics & $\begin{array}{l}\text { Number of } \\
\text { participants (\%) }\end{array}$ \\
\hline Age group & \\
$\quad<40$ years old & $66(19.52 \%)$ \\
$>40$ year old & $247(73.08 \%)$ \\
Missing data & $25(7.4 \%)$ \\
Functions & \\
Quality office/department in patient health and safety/ & \\
risk management & $75(22.19 \%)$ \\
Hospital quality and safety commission & $61(18.05 \%)$ \\
Primary care quality and safety commission & $52(15.38 \%)$ \\
Local coordination of PPCIRA & $37(10.94 \%)$ \\
Pharmacy and therapeutic commission & $15(4.44 \%)$ \\
Missing data & $78(23.08 \%)$ \\
Years of work in that unit/department & \\
$<5$ years & $139(41.12 \%)$ \\
6 to 10 years & $79(23.37 \%)$ \\
11 to 15 years & $37(10.94 \%)$ \\
$>16$ years & $42(12.43 \%)$ \\
Missing data & $41(12.13 \%)$
\end{tabular}

39) reported this availability of resources as very adequate.

The main causes for the low availability of resources are the lack of dedicated time $(37.1 \% ; n=101)$, the lack of human resources $(33.1 \% ; n=90)$, the lack of support from institutions and/or intermediate leaders $(16.2 \% ; n=$ $44)$, and the lack of technical resources/information systems $(8.1 \% ; n=22)$.

d) Training on Patient Safety. Out of a total of the 338 respondents, $70.71 \%(n=239)$ revealed that their institution promoted/developed quality and patient safety training. It should also be noted that $89.4 \%(n=302)$ of the participants considered it is "very important" to increase training in the quality, patient safety, and risk management topics, for teams from different departments/services and units in their institution.

e) Patient Safety Actions in Public Health Emergency Response. Most respondents reported that patient safety recommended actions for public health emergency response were very low $(38.2 \% ; n=129)$ or low $(33.7 \% ; n=$ $114)$, as in the pandemic context.

f) NPPS 2015-2020 Guidelines Suitability to the Organizational Context. We found that only $19.2 \%$ of respondents $(n=65)$ considered that NPPS 2015-2020 guidelines were highly suitable to the organizational context and $21 \%(n=71)$ rated the monitoring process of the NPPS 2015-2020 implementation as high. Most respondents consider that the suitability of the plan was moderate in their institutions.

Contributions to the Portuguese NPPS 2021-2026 g) Local, Regional, and National Alignment. The support and/or alignment between structures at the local, regional, and national level was considered moderate, weak, or very weak by most of the respondents, either in terms of planning ( $n=267 ; 79 \%)$, implementation $(n=277$; $82 \%)$, or monitoring $(n=273 ; 81 \%)$. More information is in Table 4.

iii) Strategic Objectives, Recommended Actions and Defined Goals Developed under the 2015-2020 NPPS

NPPS actions were organized in nine strategic objectives, following different areas of intervention considered as a priority for patient safety: organizational safety culture, communication, safe medication, safe surgery, patient identification, pressure ulcers prevention, systematic notification, analysis and prevention of adverse events, prevention and control of infections and antimicrobial resistance

We found some differences at the level of patient safety initiatives and dissemination of the same across the different strategic objectives. Initiatives on safety culture, communication, safe surgery, and safe medication were the least disseminated of all NPPS strategic objectives. On the other hand, actions focused on preventing and controlling infections and antimicrobial resistance were the most disseminated $(50.89 \%, n=172)$ and with the highest level of development $(45.86 \%, n=155)$ in healthcare organizations and also the highest rate of communication 
Table 4. Survey results: evaluation of 2015-2020 NPPS implementation and articulation between the local, regional, and national levels

\begin{tabular}{lll}
\hline Variable $\quad$ Classification & $\begin{array}{l}\text { Number of } \\
\text { participants (\%) }\end{array}$ & Limitations and needs identified by the participants \\
\hline
\end{tabular}

Involvement of the clinical teams and managers on patient safety actions

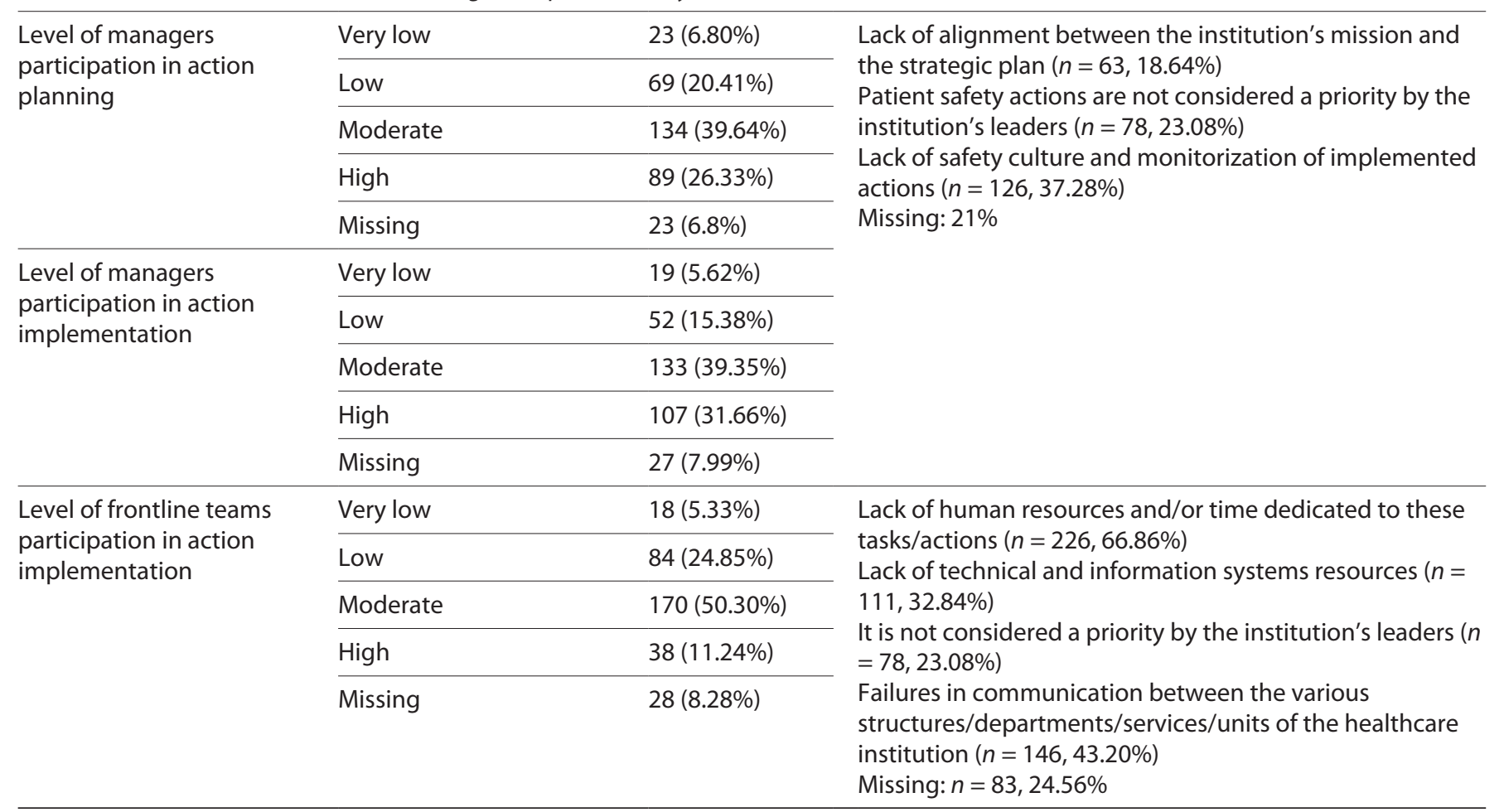

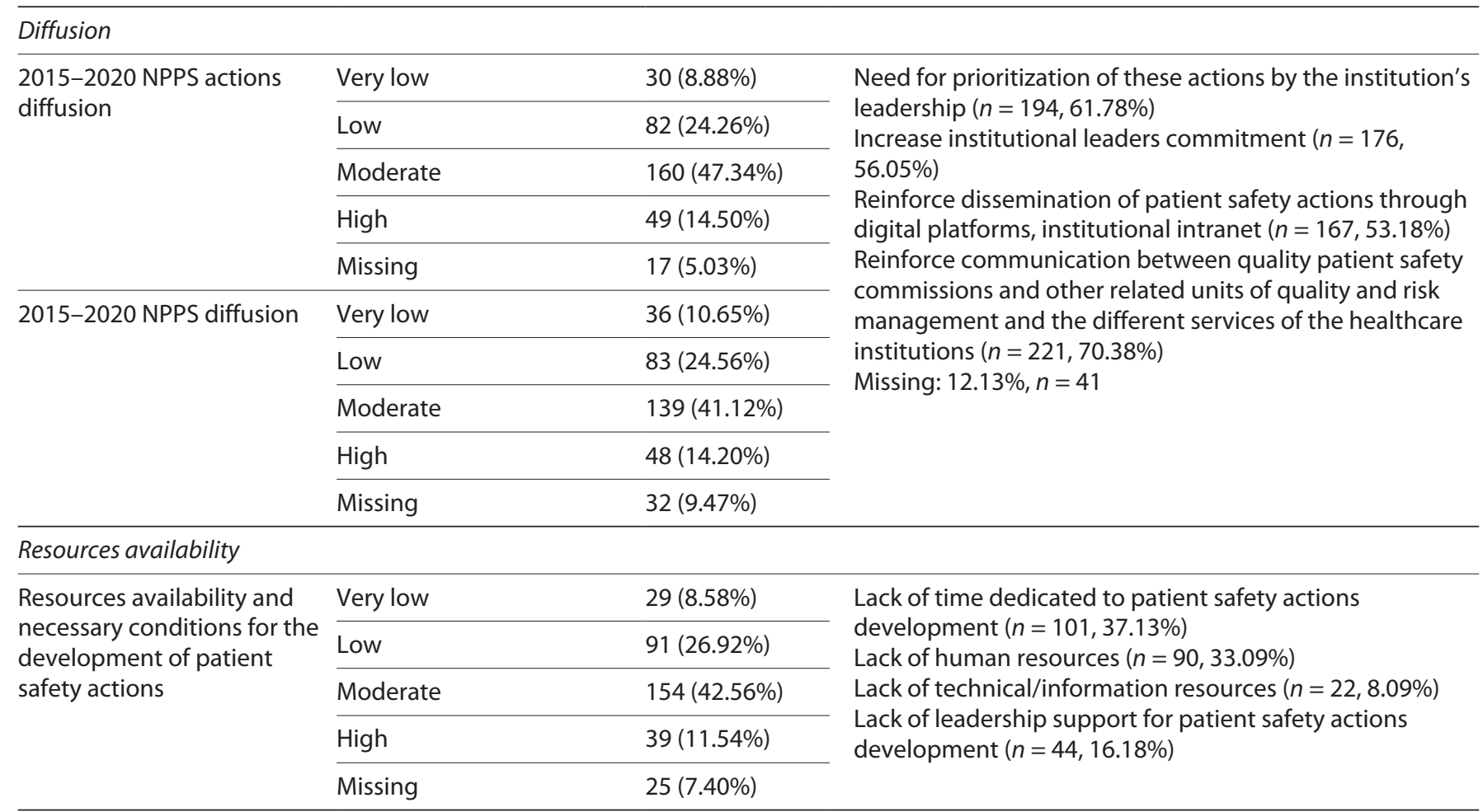


Table 4 (continued)

\begin{tabular}{ll}
\hline Variable $\quad$ Classification & $\begin{array}{l}\text { Number of } \\
\text { participants (\%) }\end{array}$
\end{tabular}

Strategic goals and deadlines adequacy on health organizations

\begin{tabular}{|c|c|c|c|}
\hline \multirow{4}{*}{$\begin{array}{l}\text { Adequacy of the PNSD } \\
\text { guidelines to the } \\
\text { organizational context }\end{array}$} & Very low & 11 (3.25\%) & \multirow{7}{*}{$\begin{array}{l}\text { Barriers identified for most strategic objectives : } \\
\text { Excessive work/lack of time of professionals/not having } \\
\text { dedicated time/reserved for these tasks } \\
\text { Lack of professionals motivation } \\
\text { Devaluation of the need of patient safety action as a } \\
\text { priority for healthcare institution } \\
\text { Lack of organizational condition and resources for the } \\
\text { action development }\end{array}$} \\
\hline & Moderate & 169 (50.00\%) & \\
\hline & High & 65 (19.23\%) & \\
\hline & Missing & 39 (11.54\%) & \\
\hline \multirow{3}{*}{$\begin{array}{l}\text { Adequacy of monitorization } \\
\text { process }\end{array}$} & Moderate & $153(45.27 \%)$ & \\
\hline & High & 71 (21.01\%) & \\
\hline & Missing & 42 (12.43\%) & \\
\hline
\end{tabular}

Training on patient safety

\begin{tabular}{lll}
\hline Training on quality of health, & Not important & $0(0 \%)$ \\
\cline { 2 - 3 } $\begin{array}{l}\text { patient safety, and risk } \\
\text { management for the teams } \\
\text { of the different departments/ }\end{array}$ & Quite important & $3(0.89 \%)$ \\
\cline { 2 - 3 } $\begin{array}{l}\text { services and units of your } \\
\text { institution }\end{array}$ & Very important & $30(8.88 \%)$ \\
\cline { 2 - 3 } & Missing & $302(89.35 \%)$ \\
\hline
\end{tabular}

No information available

Emergency crises response

\begin{tabular}{|c|c|c|c|}
\hline \multirow{5}{*}{$\begin{array}{l}\text { Adequacy of the patient } \\
\text { safety actions for emergency } \\
\text { crises response }\end{array}$} & Very low & $129(38.17 \%)$ & \multirow[t]{16}{*}{ No information available } \\
\hline & Low & $114(33.73 \%)$ & \\
\hline & Moderate & $70(20.71 \%)$ & \\
\hline & High & $10(2.96 \%)$ & \\
\hline & Missing & 15 (4.44\%) & \\
\hline \multicolumn{3}{|c|}{ Local, regional, and national articulation } & \\
\hline \multirow{5}{*}{$\begin{array}{l}\text { Planning the actions of the } \\
2015-2020 \text { PNSD and Safety } \\
\text { quality commission Action } \\
\text { Plans }\end{array}$} & Very low & $22(6.51 \%)$ & \\
\hline & Low & $85(25.15 \%)$ & \\
\hline & Moderate & $160(47.34 \%)$ & \\
\hline & High & 37 (10.95\%) & \\
\hline & Missing & $34(10.10 \%)$ & \\
\hline \multirow{5}{*}{$\begin{array}{l}\text { Implementation and } \\
\text { development of PNSD 2015- } \\
2020 \text { actions and Safety } \\
\text { quality commission Action } \\
\text { Plans }\end{array}$} & Very low & $26(7.69 \%)$ & \\
\hline & Low & $88(26.04 \%)$ & \\
\hline & Moderate & $163(48.22 \%)$ & \\
\hline & High & $28(8.28 \%)$ & \\
\hline & Missing & $33(9.76 \%)$ & \\
\hline
\end{tabular}


Table 4 (continued)

\begin{tabular}{|c|c|c|c|}
\hline Variable & Classification & $\begin{array}{l}\text { Number of } \\
\text { participants (\%) }\end{array}$ & Limitations and needs identified by the participants \\
\hline \multirow{4}{*}{$\begin{array}{l}\text { Follow-up/monitoring of the } \\
\text { actions of the } 2015-2020 \\
\text { NPPS or the safety quality } \\
\text { commissions action Plan }\end{array}$} & Very low & $30(8.88 \%)$ & \\
\hline & Low & $94(27.81 \%)$ & \\
\hline & Moderate & $149(44.08 \%)$ & \\
\hline & Missing & $38(11.24 \%)$ & \\
\hline
\end{tabular}

and discussion of the results from action implementation in multidisciplinary meetings from different departments/services/units $(44.38 \%, n=150)$.

Regarding the barriers of NPPS action implementation, we identified five main barriers: i) "Excessive work/ lack of protected time for these tasks," ii) "Lack of health professionals' motivation," iii) "Lack of actions prioritization from healthcare organizations, leaders, and teams," iv) "Lack of conditions/resources to develop these actions," and v) weak safety culture.

Safety culture actions had the highest level of concern among patient safety frontline workers. For safety culture actions $82.61 \%(n=209)$ participants that assessed the level of development as very low/low/moderate refer that there is "Excessive work/lack of time of professionals/lack of dedicated time/reserved for these tasks" and 57.31\% ( $n$ $=145$ ) refer that there is a "lack of actions prioritization from healthcare organizations, leaders, and teams."

We also highlight that $50.30 \%(n=83)$ of the participants who assessed the level of development as very low/ low/moderate referred that there is room for improvement on health professionals' motivation for developing actions in the area of safe surgery.

Regarding the implementation of pressure ulcers prevention initiatives, $41.96 \%(n=60)$ of the respondents mentioned that the main barriers for improving patient safety were the existing conditions and lack of resources (Table 5).

iv) Priorities for the Next NPPS (2021-2026)

Most of the respondents refer to the importance of a continuum of work based on the previous strategic objectives and patient safety recommended actions defined in previous NPPS (2015-2020). The most valued dimension was organizational safety culture, referred to as the main priority for the next NPPS (2021-2026) by $41.7 \%(n=$
141) of the respondents. Detailed results are described in Table 6.

When asked about new relevant areas to include in the next NPPS (2021-2026), most of the respondents considered the dimension "Health and safety of the healthcare professionals/teams" as a priority area for improvement $(n=226 ; 68.5 \%)$. The second most relevant area was " $\mathrm{Pa}$ tient safety in the new model of healthcare provision (i.e., telemedicine, home hospitalization, home care, etc.)" ( $n$ $=161 ; 48.8 \%$ ), followed by the dimension "Patient and family involvement" ( $n=158 ; 47.9 \%)$ and "Development of programs to support professional(s) or team(s) involved in an adverse event" $(n=158 ; 47.9 \%)$. Table 7 details these results.

\section{Data Collection - Interviews}

In our study, we conducted 21 online interviews with national $(n=18)$ and international $(n=3)$ experts with a large experience in quality and patient safety issues. The results obtained allowed gathering information on the strengths and weaknesses of the NPPS (2015-2020), the difficulties, barriers, and facilitators of its implementation process, as well as suggestions for improving the next NPPS 2021-2026. Table 8 describes the main results of the interviews conducted.

\section{Focus Group}

We developed two online focus groups with approximately 90 min each, using the Zoom platform. Each focus group was led by a research group member; an observer was present to assist the moderator and a secretary to take notes of the discussion. Focus group meeting was not recorded to avoid limiting the group interaction and communication. Each group was constituted by seven different patient safety experts representative of hospitals, primary healthcare settings, and educational organizations 


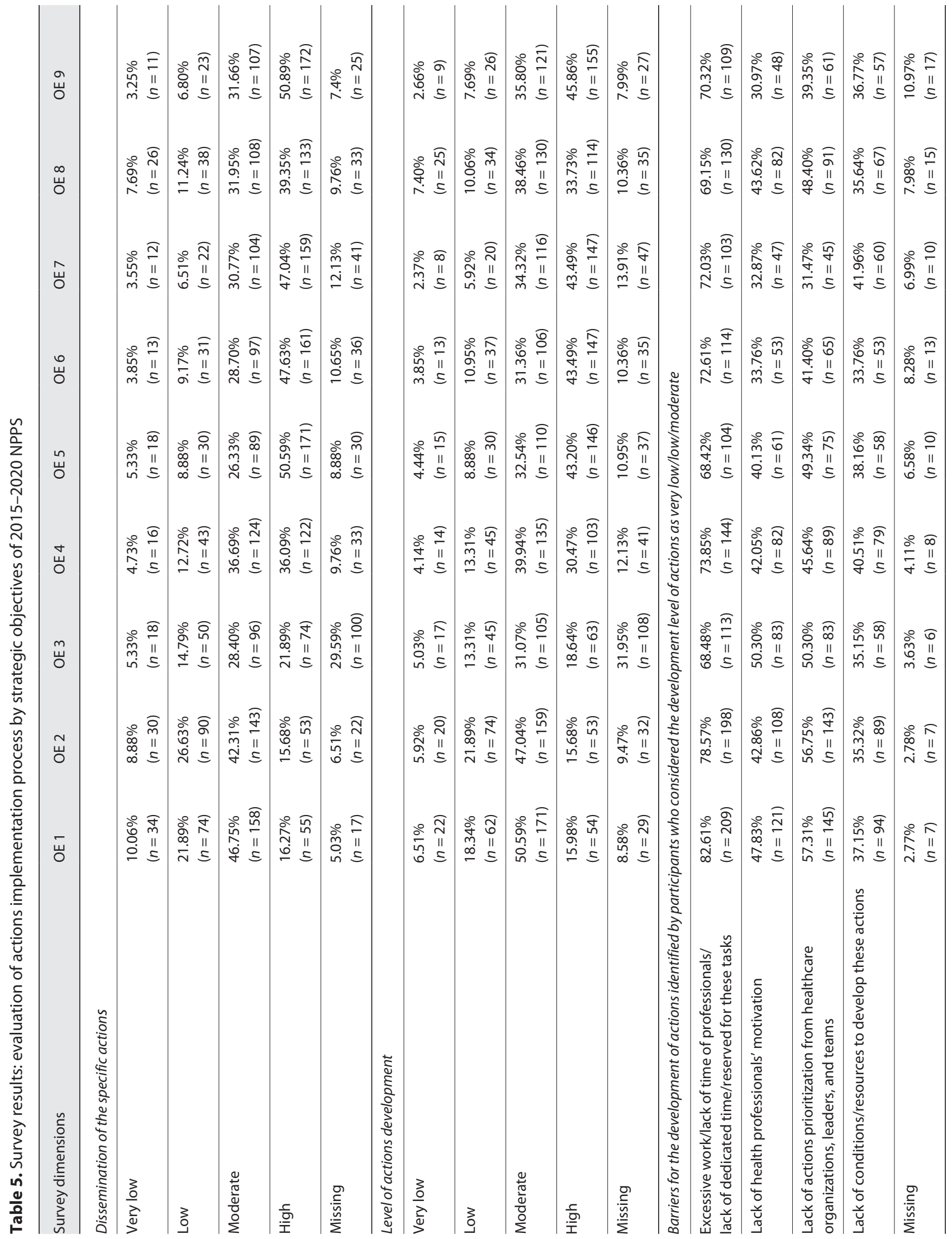




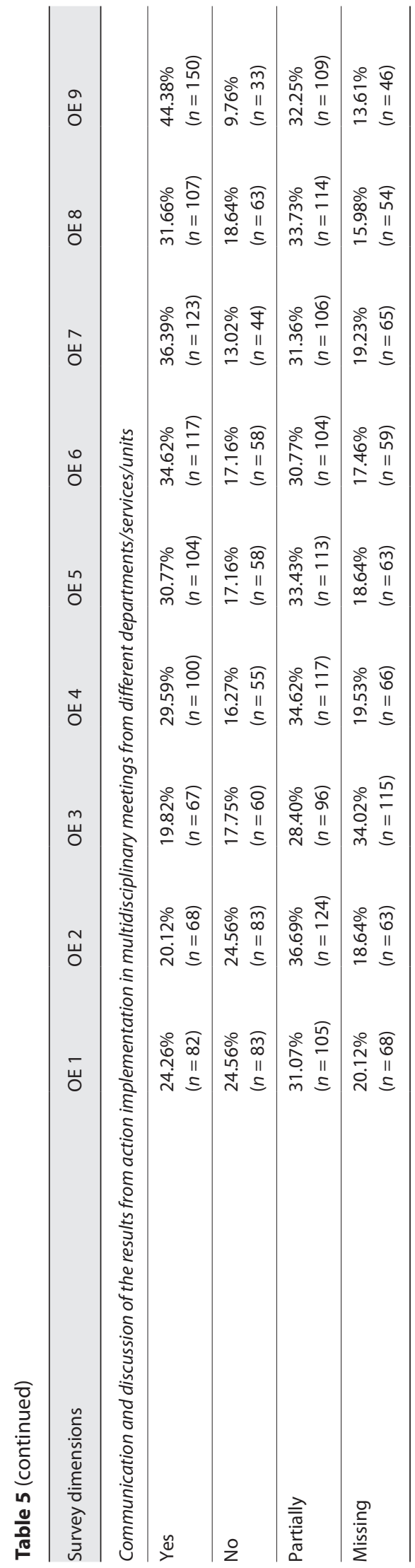

for discussing the main patient safety areas of intervention and specific goals.

The main topics that emerged from the discussion were the importance of strengthening safety culture and providing available time for patient safety actions development in health institutions, patient safety education/ training, communication, and patient involvement.

\section{Discussion}

In our study, we describe the main priorities for patient safety implementation actions based on international and national orientations, the perspectives of patient safety experts and frontline workers from quality and safety committees regarding the implementation of the Portuguese National Plan for Patient Safety (NPPS) 2015-2020 and we also get a set of recommendations for the next NPPS (2021-2026) for strengthening systematic and continuous execution of bundles of related initiatives, aspiring safer healthcare as a whole.

Isolated patient safety initiatives will not bring progress to achieve a goal [30]. To enhance the sustainability of patient safety actions it is necessary to have a clear and oriented strategy, structures, and embedded learning processes, including measurement and human resources systems, based on transformative learning models [31, 32].

A positive aspect mentioned in our study was the clear definition of goals of the NPPS 2015-2020. Having a clear and regularly defined goal monitoring is in line with other national plans structures as well $[5,8,29,30]$.

According to our collected data, strategic planning for patient safety in Portugal and elsewhere is considered an important contributor to an organizational learning environment in healthcare. This enhances teamwork, continuous and shared learning among health institutions, inherent properties of these types of organizations [33].

The consultation process with patient safety experts and healthcare frontline workers highlighted that there is an encouragement of institutional training with multiple possibilities for interaction in multidisciplinary teams and there is a high level of awareness about the need for training in patient safety. The need for inter-professional learning in patient safety follows the recommendation of other international guidelines [34-36].

Evidence has been shown that education and training are crucial to enhance patient safety and quality of care, reflected in patient outcomes improvement $[34,37]$. The Institute of Medicine report "To Err is Human," pub- 
Table 6. Priorities for the next NPPS

\begin{tabular}{ll}
\hline Priority areas for the next NPPS & $\begin{array}{l}\text { Number of } \\
\text { participants (\%) }\end{array}$ \\
\hline Organizational safety culture & $141(41.72 \%)$ \\
Infections and antimicrobial resistance prevention and control & $134(39.64 \%)$ \\
Systematic notification, analysis, and prevention of adverse events & $131(38.76 \%)$ \\
Communication in patient safety & $124(36.69 \%)$ \\
Medication safety & $123(36.39 \%)$ \\
Patient identification & $116(34.32 \%)$ \\
Falls prevention & $100(29.59 \%)$ \\
Pressure ulcers prevention & $93(27.51 \%)$ \\
Safe surgery & $83(24.56 \%)$ \\
All the mentioned options & $202(59.76 \%)$ \\
\hline & $338(100 \%)$
\end{tabular}

Table 7. New areas of interest for future NPPS

Priority new areas for patient safety improvement

Number of participants (\%)

Health and safety of the healthcare professionals/teams

$226(68.48 \%)$

Patient safety in the new modalities of healthcare provision (i.e., telemedicine, home hospitalization, home care, etc.)

$161(48.79 \%)$

Patient and family involvement

Develop support programs to support professional(s) or team(s) who were involved in the adverse event

$158(47.88 \%)$

$158(47.88 \%)$

Ensure leadership involvement in quality and patient safety improvement

$156(47.27 \%)$

Safety of new technologies/digital approach to patient safety

$138(41.82 \%)$

$129(39.09 \%)$

Emergency crisis support on public health

$101(30.61 \%)$

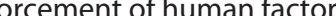

$88(26.67 \%)$

Prevent diagnostic errors

$79(23.94 \%)$

$338(100 \%)$

lished in 2000, states that "healthcare organizations and teaching institutions should participate in the development and use of simulation for training novice practitioners, problem solving, and crisis management, especially when new and potentially hazardous procedures and equipment are introduced" [1]. The World Health Organization published in 2011 the Patient Safety curriculum guide - multi-professional edition, which has now been revised and brought up to date, and it is supposed to come out during the first semester of 2022.

Patient safety initiatives contribute to reinforcing safety culture in healthcare organizations [38]. Safety culture is an important pillar for the sustainability of a learning environment and for building an atmosphere of trust and support in healthcare organizations [39]. This was the most valued dimension of the Portuguese NPPS by frontline patient safety teams and there is a strong incentive to strengthen it in the future at a national level.
Safety culture is also one of the underpinning values to shape the development and implementation of the WHO Global Patient Safety Action Plan 2021-2030: towards eliminating avoidable harm in healthcare [16] and is also included in several national plans for patient safety $[6,10$, 38].

Although there is a clear understanding of the importance of strengthening safety culture in healthcare organizations, most of the frontline workers and patient safety experts consider that there is fragile safety culture in health organizations and a lack of monitoring of implemented actions. A systematic review published in 2018 that focused on hospital safety culture evaluation revealed that most of the hospitals had underdeveloped or weak patient safety organizational culture and that there was a need for monitorization of safety-related changes and outcomes [40]. 
Table 8. Interviews summary results

\begin{tabular}{|c|c|}
\hline Strengths of $2015-2020$ NPPS & $\begin{array}{l}\text { - Measurable goals and indicators } \\
\text { - Normative scope } \\
\text { - Integrative approach using National Strategy for Quality and Safety, European Patient Safety policies, and WHO } \\
\text { guidelines } \\
\text { - Incite a learning environment } \\
\text { - Encourage institutional training and multidisciplinary teams interaction } \\
\text { - Patient safety actions proposed } \\
\text { - Clarity of information } \\
\text { - Include safety, biosafety, and prevention orientations } \\
\text { - Establishment of Quality and Safety Committees at the health organizations level, responsible for developing } \\
\text { annual reports and action plans } \\
\text { - Creation of a digital platform available for consultation by all health organizations, promoted and stimulated the } \\
\text { monitoring of results as safety culture of health organizations }\end{array}$ \\
\hline Weaknesses of 2015-2020 NPPS & $\begin{array}{l}\text { - Lack of health professionals, experts, and patients' involvement in the patient safety actions, motivated by lack of } \\
\text { motivation and awareness } \\
\text { - Lack of proximity and interaction between General Health direction, services, and professionals } \\
\text { - Lack of legislation that provides confidentiality and protection to professionals involved in/reporting an adverse } \\
\text { event } \\
\text { - Weak monitoring process that limits operationalization of the annual reports and action plans } \\
\text { - Limited local access to annual plans results } \\
\text { - Absence of an effective communication between the General Health direction and institutions, at the local level } \\
\text { - Lack of dedicated time for developing patient safety actions and other type of related task in healthcare } \\
\text { institutions } \\
\text { - The NPPS presentation is not user-friendly, focused mainly on formal and legal documentation } \\
\text { - Information mainly focused on hospitals and primary healthcare sector, and less suitable to other types of } \\
\text { disciplines, settings, and care levels }\end{array}$ \\
\hline $\begin{array}{l}\text { Strategic objectives, goals, actions, } \\
\text { and indicators of the } 2015-2020 \\
\text { NPPS }\end{array}$ & $\begin{array}{l}\text { - The targets are too ambitious and sometimes unrealistic for some healthcare organizations } \\
\text {-Importance of involving multidisciplinary teams on NPPS goals and targets definition } \\
\text { - Creation of dashboards can help monitorize the healthcare institutional targets } \\
\text { - Improve strategic goals, targets, and action dissemination among clinical teams }\end{array}$ \\
\hline Inputs for the 2021-2026 NPPS & $\begin{array}{l}\text { - Incentives to health organizations that present good results on patient safety actions should be encouraged } \\
\text { - Englobing all workers of healthcare settings in NPPS actions } \\
\text { - Patient and family involvement in patient safety } \\
\text { - Digital transition (safe communication at a digital level and data protection) } \\
\text { - Improve safety and health of clinical teams guidelines and actions } \\
\text { - Improve public awareness of patient safety topics } \\
\text { - Encourage the development of improvement plans } \\
\text { - Involve and commit leaders to implementation of NPPS in healthcare organizations }\end{array}$ \\
\hline
\end{tabular}

In our study, we also found that there is space for improvement between national, regional and local levels when it concerns patient safety action implementation, monitoring, and communication, and that this can limit the operationalization of the annual institutional action plan. Evidence shows that hierarchical culture was correlated with a lower safety climate [41].

Self-monitoring systematic processes are recommended by Finnish National Patient Safety Strategy for making immediate local changes in health organizations [10].

Local limitations identified in our study were the lack of resources and available time for dedicating to patient safety actions. Studies have shown a clear association be- tween fatigue and burnout among healthcare workers and patient safety hazards [42]. On another way, organized workflows that generate autonomy for health professionals and planning improve patient safety in healthcare organizations $[42,43]$. Therefore, it is urgent to increase dedicated time for developing patient safety actions and monitoring for better patient safety and patient outcomes.

At the major level, there is the need to integrate patient safety strategies and intervention in all levels of care, across the continuum of care. This is also one of the recommended strategies on Global Patient Safety Action Plan 2021-2030 [16]. Previous NPPS 2015-2020 was 
mostly focused on hospitals and primary care settings; however, there is the need for including other levels of care, medical areas, and adequate care through the different stages of life.

Another limitation of the Portuguese NPPS 20152020 implementation was the lack of leaders' involvement in the planning and implementation of the patient safety actions. Senior and middle leaders are recognized as important actors for patient safety actions implementation at the local and national level, providing support to the workforce, adequate and necessary conditions for implementing and monitoring the procedures, and actions to improve patient safety $[8,44]$. The lack of involvement may be caused by a lack of alignment between the institution's mission, priorities, and patient safety strategic plan.

In our study, we identify as a threat for NPPS implementation the prolonged and stressful work during the COVID-19 pandemic that is seriously affecting the work capacity of healthcare systems in healthcare settings [45]. Heavy workloads to respond to all types of health needs from COVID-19 patients and non-COVID-19 patients, decreased health professionals' dedicated time $[45,46]$ including for patient safety actions implementation and monitorization. It is important to mention that the lack of resources and dedicated time had already been identified as barriers to the participation of healthcare professionals in the development, implementation, and monitoring of patient safety initiatives before the COVID-19 pandemic started. This led us to conclude that there is a high risk of NPPS actions being unprioritized, due to the high level of stress, healthcare team's exhaustion, and the need for rapid response in healthcare settings. At the same time, COVID-19 brought a shared commitment as never before among healthcare teams, working in collaboration and having rapid adaptation to safety practices and orientations [16].

In this line, we found that patient safety actions need to be improved to respond to public health emergency crises.

Our study showed that the majority of frontline workers and interviewed patient safety experts agreed that the health and safety of healthcare providers should be taken as a priority in the next NPPS. Healthcare settings are facing a huge resilience challenge in the COVID-19 pandemic and this crisis strongly increased the awareness for health professionals support and well-being [46]. Supporting the healthcare workforce, including clinical and non-clinical workers, is a growing discussion topic in the patient safety agenda [47]. We believe that this is an opportunity for improving conditions and integrated strategies for supporting healthcare workers.

Contributions to the Portuguese NPPS 2021-2026
We also found that there is a patient safety concern among experts and frontline workers about the use of new modalities of healthcare (such as telemedicine, home hospitalization, home care). Evidence shows that it is still unclear how telehealth training addresses patient safety issues [48]. Creating digital solutions for improving patient safety is also one of the recommended strategies of the Global Patient Safety Action Plan 2021-2030 [16]. Telehealth is growing in health services and there is a clear need for investment in patient safety orientation and strategies in future NPPS.

Another opportunity for improvement future NPPS identified in our study was the need to reinforce patient and family involvement in safety issues. Patient and family engagement is a strategic objective of the WHO Global Patient Safety Action Plan 2021-2030 and is also a common and valued pillar in patient safety strategic plans from other countries such as Spain, England, Scotland, and Finland $[5-7,10,16]$. Moreover, patient safety experts agree that public awareness of patient safety topics should be strengthened for encouraging patients and families to actively participate in care.

\section{Findings and Proposed Framework for the NPPS} 2021-2026

Based on the findings and insights of this study we propose that NPPS 2021-2026 must include a balance between innovation and continuity. Therefore, the future NPPS should maintain the majority of strategic objectives defined in the previous NPPS 2015-2020 and follow the six international goals and go along with the new challenges emerging in the healthcare systems.

The recent WHO Global Patient Safety Action Plan 2021-2030 should inspire countries to develop their respective patient safety national action plans oriented by Pillars, Strategic Objectives, and Actions [16].

We believe that following the same structure at a global level will reinforce the alignment between the national and international patient safety vision.

Thus, our conceptual framework proposal for the elaboration of the NPPS 2021-2026 is focused on:

With the final aim of promoting a continuous improvement of patient safety - across different contexts and healthcare levels, reflecting integration and continuity of care - we strongly suggest that the future NPPS (2021-2026) should include the following aspects:

\section{Limitations}

A complex data collection process and analysis were undertaken and therefore, some limitations should be 
mentioned. The interviews and focus group meetings were not recorded. This can lead to the loss of information in the data collection process.

Regarding the survey data collection, it was not possible to identify the total population of Quality and Safety Committee members and, therefore, the response rate was not possible to quantify. However, based on $338 \mathrm{com}$ pleted surveys from 95 Quality and Safety Committees we can assume that we had a high level of participation at a national level and we strongly believe that the results obtained are representative of the reality of the institutions of the Portuguese NHS.

\section{Conclusion}

The definition of a strategic plan, as a completely valid and useful tool for guiding all types of organizations, including healthcare organizations, is a very important process to define priorities, identify which actions must be implemented and how, and the role that each stakeholder must take on. Thus, the alignment required in the definition and implementation of a strategic plan is never easy.

A strategic planning process is essential to help different stakeholders make a successful transition from what has been to what is now and to what will be in the future. Due to the recent and important movements that we have been witnessing, both at national and international levels in patient safety, it is clear that the definition and implementation of a national plan for patient safety is a crucial issue for health planning, health quality, and health system innovation.

The main purpose of the conceptual and operational proposals presented to the DQH/DGH for the Portuguese National Plan for Patient Safety 2021-2026 is to "Improve patient safety across the care continuum," carried out based on key areas that healthcare institutions, at all levels of care and degrees of maturity, must prioritize and develop to strengthen them. These key areas are called Pillars. For each of these Pillars, several recommendations have been highlighted in our analysis and systematized in the results section. Healthcare institutions must incorporate these recommendations into their patient safety policies and strategies.

Together with the conceptual framework defined for the NPPS 2021-2026, there needs to be a set of laws, norms, and directives approved by the competent entities, as well as a measurement and monitoring plan. This framework emphasizes the importance of making patient safety a priority in health policies and strategies at the local, regional, national, and international levels.

In conclusion, this study presents an innovative and robust proposal for the next Portuguese National Plan for Patient Safety (2021-2026), without being disruptive. This plan can be used as a tool for strategic action and continuous improvement of patient safety across a variety of contexts and health service levels, reflecting integration and continuity of care. To be successful, the plan requires, as stated in this proposal, an active patient, family/caregiver participation and a greater commitment and engagement of the leaders, healthcare professionals, and all stakeholders involved. Partnerships between local, regional, and national healthcare institutions/entities need to be reinforced, and the alignment between the institutions' missions and safety priorities is crucial to enhance patient safety. Additionally, this work highlights the added value for health systems achieved through strong partnerships between public administration and academic institutions to improve healthcare quality and patient safety.

\section{Acknowledgement}

The authors would like to thank all members of the Quality and Safety Committee at the hospitals and the primary care centers that were involved in the survey; the national and international experts who were interviewed; and the team of ESEL for their work in the analysis of the Annual reports of the NPPS 2015-2020. We would also like to thank the members of the NPPS consulting group nominated to support the development of the framework for the NPPS 2021-2026 proposal and the experts that participated in the Focus, including the members of the NPPS consulting group.

\section{Statement of Ethics}

The authors declare that they complied with ethical principles according to the Declaration of Helsinki. Subjects who have participated in the survey, interview, and focus groups have given their informed consent. Privacy of research subjects and the confidentiality of their personal information was taken. In our study, ethics approval was not required.

\section{Conflict of Interest Statement}

The research team of the National School of Public Health were responsible for the methodological design of the study, collection and analysis of data. Even though V.F. is the Director of DQH and C.P. works in the same department, it must be made clear that they were in no way whatsoever involved in the methodological design and data collection, analysis, and discussion presented in this paper. 


\section{Funding Sources}

This research was based on the fieldwork developed by the research team of the National School of Public Health, NOVA University of Lisbon and the data collection process for the development of the National Plan of Patient Safety 2021-2026 strategic framework proposal. The fielwork and data collection process was funded by the Directorate-General of Health (DGH).

\section{Author Contributions}

P.S. and S.G.P.: conception and design of the research. S.G.P. and M.J.L. were involved in the data collection and analysis, methodological implementation, and results. A.L.V.-I., C.P., and V.F. were involved in the literature review and review of national and international documentation. P.S., S.G.P., M.J.L.: discussion of results and conclusion. A.L.V.-I., C.P., and V.F. revised the manuscript. All authors read and approved the final manuscript.

\section{References}

1 Institute of Medicine (US) Committee on Quality of Health Care in America. To err is human: building a safer health system. Kohn LT, Corrigan JM, Donaldson MS, editors. Washington, DC: National Academies Press; 2000.

2 Garrouste-Orgeas M, Philippart F, Bruel C, Max A, Lau N, Misset B. Overview of medical errors and adverse events. Ann Intensive Care. 2012;2(1):2

3 Vincent C, Staines A. Enhancing the quality and safety of Swiss healthcare: a national report commissioned by the Federal Office of Public Health on the quality and safety of healthcare in Switzerland. Bern: Federal Office of Public Health; 2019.

4 SPF Santé Publique. Troisième programme pluriannuel de qualité et de sécurité des patients 2018-2022. Bruxelles: SPF Santé Publique; 2018 [cited 2021 Oct 12]. Available from: https: //www.health.belgium.be/fr/ troisieme-programme-pluriannuel-2018-2022.

5 NHS England; NHS Improvement. The NHS patient safety strategy: safer culture, safer systems, safer patients. London: NHS Improvement; NHS England; 2019.

6 Healthcare Improvement Scotland. Scottish patient safety programme. Edinburgh: NHS Scotland; 2021 [cited 2021 Oct 14]. Available from: www.healthcareimprovementscotland. org/our_work/patient_safety/spsp.aspx.

7 Ministerio de Sanidad Servicios Sociales e Igualdad. Estrategia de Seguridad del Paciente del Sistema Nacional de Salud: período 2015-2020. Madrid, Spain: Ministerio de Sanidad, Servicios Sociales e Igualdad; 2016.

8 Health Service Executive. Patient safety strategy 2019-2024. Dublin, Ireland: Health Service Executive; 2019 [cited 2021 Oct 12]. Available from: https://www.hse.ie/eng/ about/qavd/patient-safety/hse-patient-safety-strategy-2019-2024.pdf.

9 ACT Government of Health. ACT health quality strategy 2018-2028: person-centred, safe, and effective care. Canberra, Australia: Australian Capital Territory; 2018.

10 Ministry of Social Affairs and Health. Patient and client safety strategy. Helsinki, Finland: Ministry of Social Affairs and Health; 2017.
11 Donaldson L, Fletcher M. The WHO World Alliance for Patient Safety: towards the years of living less dangerously. Med J Aust. 2006; 184(S10):S69-72.

12 Zsifkovits J, Zuba M, Geißler W, Lepuschütz L, Pertl D, Kernstock E, et al. Costs of unsafe care and cost effectiveness of patient safety programmes. Brussels: European Commission; 2016.

13 Slawomirskii L, Auraaeni A, Klazingai N. The economics of patient safety: strengthening a value-based approach to reducing patient harm at national level. Paris: Organisation for Economic Co-operation and Development; 2017 [cited 2021 Oct 12]. Available from:

14 Organisation for Economic Co-operation and Development. The economics of patient safety in primary and ambulatory care: flying blind. Paris: Organisation for Economic Cooperation and Development; 2018. OECD Health Working Papers; 106 [cited 2021 Nov 3]. Available from: https://www.oecd-ilibrary.org/social-issues-migration-health/ the-economics-of-patient-safety-in-primaryand-ambulatory-care baf425ad-en.

15 Slawomirski L, Klazinga N. The economics of patient safety: from analysis to action. Paris: Organisation for Economic Co-operation and Development; 2020.

16 World Health Organization. Global patient safety action plan 2021-2030: towards eliminating avoidable harm in health care. Geneva: World Health Organization; 2021 [cited 2021 Dec 2]. Available from: https://apps.who.int/ iris/handle/10665/343477.

17 Conselho da União Europeia. Recomendação do Conselho da União Europeia, de 9 de Junho de 2009 sobre a segurança dos pacientes, incluindo a prevenção e o controlo de infecções associadas aos cuidados de saúde (2009/C 151/01) JOUE; 2013.

18 Bates DW, Singh H. Two decades since to err is human: an assessment of progress and emerging priorities in patient safety. Health Aff. 2018;37(11):1736-43.

19 Leistikow I, Kalkman C, de Bruijn H. Why patient safety is such a tough nut to crack. BMJ. 2011;342:d3447.

20 Wachter RM. Patient safety at ten: unmistakable progress, troubling gaps. Health Aff. 2010;29(1):165-73.
21 Yu A, Flott K, Chainani N, Fontana G, Darzi A. Patient safety 2030. London: NIHR Imperial Patient Safety Translational Research Centre; 2016

22 Baines RJ, Langelaan M, de Bruijne MC, Asscheman H, Spreeuwenberg P, van de Steeg L, et al. Changes in adverse event rates in hospitals over time: a longitudinal retrospective patient record review study. BMJ Qual Saf. 2013; 22(4):290-8

23 Sousa P, Uva AS, Serranheira F, Uva MS, Nunes C. Patient and hospital characteristics that influence incidence of adverse events in acute public hospitals in Portugal: a retrospective cohort study. Int J Qual Health Care. 2018;30(2):132-137.

24 Donaldson L, Ricciardi W, Sheridan S, Tartaglia R, editors. Textbook of patient safety and clinical risk management. Cham, Switzerland: Springer; 2021.

25 Vitorino M, Aguiar P, Sousa P. In-hospital adverse drug events: analysis of trend in Portuguese public hospitals. Cad Saúde Pública. 2020;36(3):e00056519.

26 Scripcaru G, Mateus C, Nunes C. Adverse drug events: analysis of a decade: a Portuguese case-study, from 2004 to 2013 using hospital database. PLoS One. 2017;12(6):e0178626.

27 Sousa-Pinto B, Marques B, Lopes F, Freitas A. Frequency and impact of adverse events in inpatients: a nationwide analysis of episodes between 2000 and 2015. J Med Syst. 2018;42(3): e48.

28 Despacho no. 28/2015 Aprova o Plano Nacional para a Segurança dos Doentes 2015-2020 em Diário da República; 1400-A/2015. 1 Suplemento, Série II (2015-02-10): 3882(2-10).

29 The US South West Hospital and Health Service. In: South West Hospital and Health Service Safety and Quality Strategy 2018-2022. Queensland: Queensland Government; 2018. Vol. 1.

30 Zimmerman R, Ip I, Christoffersen E, Shaver J. Developing a patient safety plan. Healthc Q. 2008;11(3 Spec No):26-30.

31 Lau KW, Lee PY, Chung YY. A collective organizational learning model for organizational development. Leadersh Organ Dev J. 2019; 40(1):107-23. 
32 Cummings TG, Worley CG. Organizational development and change. 7th ed. Cincinnati, $\mathrm{OH}$ : South-Western College Publishing; 2001.

33 Leonard M. Achieving safe and reliable healthcare. Chicago, IL: Health Administrative Press; 2004.

34 UK Commission on Education and Training for Patient Safety. Improving safety through education and training. UK: Health Education England; 2016.

35 Delivering quality health services: a global imperative for universal health coverage. Geneva: World Health Organization; Organisation for Economic Co-operation and Development; The World Bank; 2018.

36 World Health Organization. WHO patient safety curriculum guide: multi-professional edition. Geneva: World Health Organization; 2011.

37 Wu AW, Busch IM. Patient safety: a new basic science for professional education. GMS J Med Educ. 2019;36(2):Doc21.
38 Weaver SJ, Lubomksi LH, Wilson RF, Pfoh ER, Martinez KA, Dy SM. Promoting a culture of safety as a patient safety strategy: a systematic review. Ann Intern Med. 2013;158(5 Pt 2):369-74.

39 Rebelo T, Gomes AD. Is organizational learning culture a good bet? An analysis of its impact on organizational profitability and customer satisfaction. Acad Rev Latinoam Adm. 2017;30(3):328-43.

40 Reis CT, Paiva SG, Sousa P. The patient safety culture: a systematic review by characteristics of Hospital Survey on Patient Safety Culture dimensions. Int J Qual Health Care. 2018; 30(9):660-77.

41 Singer S, Falwell A, Gaba DM, Meterko M, Rosen A, Hartmann CW, et al. Identifying organizational cultures that promote patient safety. Health Care Manage Rev. 2009;34(4):300-11.

42 Garcia C, Abreu L, Ramos J, Castro C, Smiderle F, Santos J, et al. Influence of burnout on patient safety: systematic review and metaanalysis. Medicina. 2019;55(9):553.
43 Hall LH, Johnson J, Watt I, Tsipa A, O’Connor DB. Healthcare staff wellbeing, burnout, and patient safety: a systematic review. PLoS One. 2016;11(7): $\mathrm{e} 0159015$.

44 Leonard M, Frankel A. Role of effective teamwork and communication in delivering safe, high-quality care. Mt Sinai J Med. 2011;78(6): 820-6.

45 Zhang M, Zhang P, Liu Y, Wang H, Hu K, Du $M$. Influence of perceived stress and workload on work engagement in front-line nurses during COVID-19 pandemic. J Clin Nurs. 2021; 30(11-12):1584-95.

46 Lobão MJ, Paiva SG, Sousa P. Second victim phenomenon in COVID-19 pandemic. Lusíadas Sci J. 2021(2):3-4.

47 Brand SL, Thompson Coon J, Fleming LE, Carroll L, Bethel A, Wyatt K. Whole-system approaches to improving the health and wellbeing of healthcare workers: a systematic review. PLoS One. 2017;12(12):e0188418.

48 Guise V, Anderson J, Wiig S. Patient safety risks associated with telecare: a systematic review and narrative synthesis of the literature. BMC Health Serv Res. 2014;14(1):e588. 